\title{
Preservação de Acervos Fílmicos no Distrito Federal
}

\author{
Preservation of Film Archives in Distrito Federal \\ Preservación de Acervos Fílmicos en el Distrito Federal
}

DOI: https://doi.org/10.1590/1809-5844202015

\section{Angélica Gasparotto de Oliveira ${ }^{1}$}

https://orcid.org/0000-0001-8325-6033

${ }^{1}$ (Università di Bologna, Dipartimento delle Arti Visive, Performative e Mediali, Dottorato in Arti Visive, Performative, Mediali. Bologna, Itália).

\section{Resumo}

Algumas reportagens relatam a perda de acervos fílmicos de pioneiros que filmaram a construção de Brasília, mostrando que não há conhecimento sobre os locais onde são armazenadas e preservadas estas produções. Com isso, o objetivo geral desta pesquisa é descrever como e onde é realizada a preservação de acervos fílmicos no DF, não só dos pioneiros, mas também de cineastas da cidade. Uma das estratégias metodológicas foi a realização de entrevistas e aplicação de questionário em instituições que abrigam filmes, em instituições coletoras de cultura e em produtoras de filmes existentes no Distrito Federal. Os resultados da pesquisa mostram que atualmente, no DF, as instituições que possuem acervos de filmes não agregam as características necessárias para preservar tais acervos. Notaram-se fortemente deficiências nos recursos humanos e nas instalações físicas que guardam os acervos. Concluiu-se que, apesar de a capital do país ter uma produção cinematográfica bastante expressiva, grande parte das instituições que abrigam de alguma forma acervos de filmes relacionados à cidade não os preserva de forma adequada.

Palavras-chave: Acervos fílmicos. Cinemateca. Distrito Federal. Filmes brasilienses. Preservação fílmica.

\begin{abstract}
Some reports about the loss of filmic collections of pioneers who filmed the construction of Brasilia have shown that there is no knowledge about the places where these productions are stored and preserved in DF. For this reason, this article presents the results obtained in a master's degree research that aimed to describe how and where the preservation of filmic collections is held in DF, not only of the pioneers but also of the local moviemakers. The methodological strategies were conducting interviews and applying questionnaires in institutions that house movies, memorabilia and Film Studios in the Distrito Federal. The research results show that currently, in DF, the institutions that store film collections do not add the necessary characteristics to preserve such collections. It is strongly noted deficiencies in human resources and in physical facilities that store
\end{abstract}


the collections. The conclusion is that, despite the capital having a very expressive filmmaking, most of the institutions that house collections of films related to the city do not preserve them properly.

Keywords: Cinematheque. Distrito Federal. Film collections. Films from Brasília. Film preservation.

\section{Resumen}

Algunos medios de comunicación han informado la pérdida de las colecciones fílmicas de pioneros que filmaron la construcción de Brasilia, lo que demuestra que no hay conocimiento público acerca de los lugares donde se almacenan y conservan estas producciones. Por ello este trabajo presenta los resultados obtenidos en la investigación de maestría que tuvo como objetivo describir cómo y dónde se lleva acabo la preservación de las colecciones fílmicas en el Distrito Federal, no sólo de los pioneros, sino también de los cineastas de la ciudad. Una de las estratégias metodológicas realizada ha sido entrevistas y cuestionarios aplicados en las instituciones que albergan películas, en instituciones culturales y en empresas productoras de vídeos en el Distrito Federal. Los resultados de la investigación muestran que actualmente, en DF, las instituciones que poseen colecciones de películas no agregan las características necesarias para preservar tales colecciones. Se observaron deficiencias en los recursos humanos y en las instalaciones físicas que protegen las colecciones.Se concluyó que, aunque la capital posea uma producción de cine muy significativa, la mayoría de las instituciones que de algun modo albergan acervos fílmicos relacionados a la historia de la ciudad no son preservados de manera adecuada.

Palabras clave: Archivos fílmicos. Cinemateca. Distrito Federal. Películas brasilienses. Preservación fílmica.

\section{Introdução}

A preservação fílmica figura como ação fundamental para a preservação da memória do mundo, uma vez que os filmes se apresentam como testemunhas do modo de vida das gerações passadas.

Dada a importância da preservação fílmica no contexto mundial, algumas organizações internacionais preocupam-se em estabelecer parâmetros de preservação para filmes, sendo a principal delas a Federação Internacional de Arquivos de Filmes (FIAF), criada em 1938 e que, atualmente, reúne arquivos de filmes do mundo inteiro para promover discussões sobre a preservação fílmica. Da mesma forma, o Programa Memória do Mundo da United Nations Educational Scientific and Cultural Organization (UNESCO) estabelece guias práticos, e o Science and Technology Council de Hollywood (Conselho de Ciência e Tecnologia de Hollywood) que lançou a publicação “O Dilema Digital” discute os problemas atuais referentes à transferência do conteúdo em película para as mídias digitais.

Esses guias com diretrizes de preservação são de suma importância, assim como congressos e reuniões para discutir os problemas relacionados à preservação de filmes, pois nota-se que grande parte dos filmes produzidos nos primeiros anos do Cinema se perderam 
para sempre por causa de sua má preservação, advinda do descaso ou da falta de conhecimento dos materiais que compõem os suportes fílmicos.

A ideia de fazer esta pesquisa surgiu devido a algumas reportagens que foram veiculadas na mídia sobre filmagens da construção da capital federal que estariam se perdendo devido à sua má preservação. Uma delas citou o acervo do engenheiro português Fernando da Glória Rosendo, que veio à Brasília para ajudar a construir o Palácio da Alvorada e filmou os procedimentos que dariam início à formação da nova capital brasileira.

Contudo, as filmagens do engenheiro permaneceram com ele até 2011, sob condições de umidade e temperatura inadequadas, quando foram entregues à sua filha Ana Maria Rosendo, residente em Brasília. A filha de Rosendo não conseguiu sequer um projetor para assistir às filmagens do pai, feitas em $16 \mathrm{~mm}$, e os filmes foram enviados à Cinemateca Brasileira de São Paulo, que aceitou guardá-los (TESOUROS..., 2011).

Situação similar ocorreu com o cinegrafista italiano Dino Cazzola, que registrou cerca de 300 horas de filmagens sobre Brasília entre 1960 e 1970. O material foi guardado no sótão da casa de Cazzola fora de condições ideais de preservação e, por isso, mais de 70 \% desse material se encontra perdido (ZANIN, 2012).

O documentário Dino Cazzola: uma filmografia de Brasília narra o estado em que foram encontrados os filmes do cinegrafista italiano, a maioria sem a mínima possibilidade de recuperação. Os rótulos dos filmes permaneceram e indicavam ser filmagens de Juscelino Kubitschek caminhando pelas obras ou fazendo discursos, entre outras preciosidades que fazem parte da memória de Brasília (DINO..., [2012]).

Portanto, a pesquisa descrita neste artigo baseou-se especificamente na análise de acervos de filmes no Distrito Federal (DF), tendo como objetivo geral descrever como e onde é realizada a preservação de acervos nesta região.

Os objetivos específicos estabelecidos foram: descrever as características desses acervos; identificar os recursos físicos e humanos para sua guarda e tratamento; identificar os critérios utilizados para a incorporação de filmes a tais acervos; identificar os métodos de preservação de acervos fílmicos em instituições da capital federal; identificar fatores relacionados à preservação e ao acesso à memória fílmica produzida/acumulada no DF; e identificar a percepção de gestores de acervos, de produtores e de cineastas do DF que possuem acervos de filmes a respeito de questões relevantes sobre tais acervos.

A metodologia utilizada para atingir os objetivos da pesquisa foi o levantamento por meio de questionário e entrevista, portanto o estudo adota abordagem mista, ou seja, qualitativa e quantitativa.

Além do levantamento bibliográfico, informações relevantes para o trabalho puderam ser encontradas nas páginas virtuais das associações de preservação audiovisual e de cinematecas.

A pesquisa se validou, em grande parte, por meio da pesquisa de campo que incluiu visitas a quatro produtoras fílmicas e instituições coletoras de cultura e seis instituições que abrigam acervos de filmes do Distrito Federal, com o intuito de avaliar as condições em 
que se encontram os acervos e coletar opiniões de cineastas e produtores de filmes sobre a preservação fílmica no DF.

Por conseguinte, o artigo estrutura-se apresentando primeiramente aspectos da construção de Brasília e da criação dos cinejornais, perpassando as organizações que recolheram o acervo de filmes criados em Brasília e sobre Brasília, para, então, proceder às entrevistas com cineastas, produtores e responsáveis por locais de preservação fílmica; e, por fim, são descritos a metodologia da pesquisa feita, seus resultados e finalmente as conclusões.

\section{Acervos de filmes no Distrito Federal}

A memória extraída de um grupo de pessoas (memória coletiva) tende a ser mais confiável do que o relato baseado na memória de um único indivíduo (memória individual). Tal fato exemplifica-se ao notar-se que as lembranças transmitidas por pioneiros, trabalhadores, cineastas, gravações de rádio, entre vários testemunhos da época da construção de Brasília, mesmo que não coincidam integralmente, mantém sua essência tornando-se mais confiáveis por advirem de um grupo de pessoas.

A preservação desses testemunhos ao longo do tempo é tão importante por fornecer às sucessivas gerações a oportunidade de agregar várias informações e as transformar em memória e história.

Quando os documentos que representam uma época são destruídos, certamente isto repercute nas gerações futuras, ainda que elas ignorem. Se o grupo de indivíduos que transferia a informação anteriormente já não existe mais, sobram apenas os suportes de informação que poderiam reconstituir as imagens vividas naquele tempo (HALBWACHS, 2006).

A construção de Brasília iniciou-se na década de 1950. Entre 1957 e 1960, várias filmagens foram feitas para registrar o período da construção e a inauguração da cidade.

Essas filmagens resultaram em três acervos de cinejornais, pequenos filmes publicitários que eram exibidos nas salas de cinema antes do longa-metragem começar, os quais foram abrigados na Companhia Urbanizadora da Nova Capital (NOVACAP), no Instituto Histórico e Geográfico do Distrito Federal (IHGDF) e no Memorial JK (ALVIM; BUENO; GUIMARÃES, 1983).

Dos três acervos, o do Memorial JK apresentou-se o maior e com mais variedade de temas. Representa o acervo pessoal de Juscelino Kubitschek, doado ao Memorial por sua mulher, Dona Sarah.

O acervo do IHGDF, quando examinado pelos técnicos da EMBRAFILME, apresentou-se o mais deteriorado.

Na década de 1980, foi criada a Fundação Nacional Pró-Memória (FNPM) da Secretaria de Cultura do Ministério da Educação, que visava resgatar a importância dos cinejornais, guardados por pessoas ou instituições, e que reproduziam por meio de imagens vários pontos de vista da construção de Brasília. 
Tendo sua memória revitalizada pelas imagens do passado, pelo som da voz governamental de então e pela música, que enfatizava este ou aquele acontecimento, os que tomaram parte naquele momento controverso [...] poderão revivê-lo e repensá-lo. Aos que, por força da distância ou da idade, dele não participaram, será facultada a oportunidade [...] de um acesso ao conhecimento, através das possibilidades que o cinema, mais do que a fotografia e a leitura dos jornais da época, permite (ALVIM; BUENO; GUIMARÃES, 1983, p. 6).

Os idealizadores da FNPM conseguiram realizar o catálogo com o conteúdo dos 25 cinejornais localizados no Memorial JK, mas, infelizmente, devido à falta de verbas, não puderam por em prática a ideia de transferir os filmes para novos suportes e restaurar aqueles que se encontravam deteriorados, como desejavam inicialmente (ALVIM; BUENO; GUIMARÃES, 1983).

Os cinejornais cessaram sua produção em 1960, quando Brasília foi inaugurada. Quatro anos depois, em 1964 e 1965, começaram a chegar em Brasília personalidades do Cinema como Nelson Pereira dos Santos, Jean Claude Bernardet, Lucila Ribeiro Bernardet e Dib Lutfi com o intuito de contribuir para a criação do Curso de Cinema da Universidade de Brasília (UnB), o primeiro do país (CARVALHO, 2002).

Paulo Emílio Salles Gomes também veio para Brasília para integrar o corpo docente do Curso de Cinema da UnB. Ele já havia morado em Paris e tido contato com os cineclubes franceses e integrou o grupo de organização da FIAF. De volta ao Brasil, criou um cineclube em São Paulo, o qual deu origem à Cinemateca Brasileira (SÁ, 2003).

Em Brasília, além de ministrar aulas na UnB em 1965, criou também o primeiro cineclube da cidade trazendo filmes da Cinemateca Brasileira de São Paulo que eram exibidos para aproximadamente duas mil pessoas e, posteriormente, discutidos em sessões de cinema abertas para a comunidade.

Ismail Xavier relata, no prefácio do livro "Cinemateca brasileira”, a importância de, ao se falar em cinematecas, mencionar "a reflexão sobre um projeto de institucionalização da pesquisa sobre cinema no Brasil que se inaugura nas cinematecas e se estende para as universidades, definindo uma parceria na produção do conhecimento e na formação" (CORREA JÚNIOR, 2010, p. 14).

Todavia, a ditadura militar encerrou as atividades do Cineclube e ordenou a demissão em massa dos professores da UnB e de praticamente todo o corpo docente do Curso de Cinema no segundo semestre de 1965.

Ainda assim, importantes filmes com a temática de Brasília foram produzidos na década de 1960, como Vestibular 70 de Vladimir Carvalho e Fernando Duarte; Brasília, ano 10, de Geraldo Sobral Rocha; Itinerário de Niemeyer, de Vladimir Carvalho; e Universidade de Brasília: primeira experiência em pré-moldado, de Heinz Forthmann (MENDES apud CAETANO, 2007). 
O cinema brasiliense passa a ter uma veia documentarista em suas primeiras produções devido à vontade dos cineastas de registrar as ações violentas dos militares tomadas dentro da UnB. Esse gênero perdurou por muito tempo na produção dos cineastas locais.

A frase de Vladimir Carvalho "A poesia do documentário é sobretudo a verdade" resume a importância desse gênero na formação da memória de Brasília e do cinema brasiliense (SÁ, 2003, p. 124).

\section{Organizações no DF}

Vladimir Carvalho era o encarregado da Associação Brasileira de Documentaristas do Distrito Federal (ABD-DF) em Brasília na época em que o Festival de Brasília estava suspenso e o Curso de Cinema na UnB havia sido extinto. Naquela época o trabalho da ABD-DF foi dificultado pelos militares e poucas pessoas se atreviam a fazer Cinema na cidade, o que enfraqueceu muito a Associação (CARVALHO, 2002).

Com o passar do tempo e a retomada da produção cinematográfica no eixo Rio-São Paulo sob a direção da EMBRAFILME, a volta do Festival de Brasília e o cumprimento da lei do curta-metragem ${ }^{1}$, o ânimo dos cineastas de Brasília foi retomado, mesmo que ainda vivendo sob o regime militar (CARVALHO, 2002).

Em 1978, quando vários filmes eram novamente produzidos na UnB, foi proposta a formalização da ABD-DF. O primeiro presidente da associação recém-oficializada foi o produtor Márcio Curi (CARVALHO, 2002).

Já na década de 1990, o cineasta Marcos de Souza Mendes, então Vice-Presidente da ABD-DF na gestão de Carlos Augusto Ribeiro Jr., elaborou um projeto para o desenvolvimento do audiovisual em Brasília que, enviado à Fundação Cultural, não obteve resposta alguma das autoridades e "dorme no limbo das gavetas até hoje" (CARVALHO, 2002, p. 304).

A partir de 1990, a ABD-DF passou a se chamar Associação Brasiliense de Cinema e Vídeo (ABCV), permanecendo com seu antigo intuito de fortalecer a classe cinematográfica brasiliense, reivindicando equipamentos de produção cinematográfica e o estabelecimento de cotas regionais de produção em editais nacionais. Essa última reivindicação tiraria a produção de filmes nacionais do famoso eixo Rio-São Paulo (MORICONI, 2012).

Em 1990, a ABCV representou o embrião do Polo de Cinema do DF. Contudo, atualmente, a instituição que poderia ser responsável pela produção de grande parte das obras fílmicas do DF sucumbiu à falta de investimentos (CARVALHO, 2002).

O Polo de Cinema, que abrigava 750 filmes em curta, média e longa metragens e gravações em formatos VHS e DVD teve que solicitar a transferência de seus filmes para o Arquivo Público do Distrito Federal (ArPDF) diante do risco de perda de seu acervo de imagens em movimento, dada a falta de investimentos no Polo, que apresentava parte do material cinematográfico deteriorado e infiltrações na construção (SÁ, 2012).

1 Artigo 13 da Lei Federal 6.281, de 9 de Dezembro de 1975. 
O ArPDF, idealizado por Walter Albuquerque Mello, foi inaugurado em 1985 - 25 anos após a criação de Brasília - com a missão de guardar os documentos dos órgãos públicos e de personalidades que contribuíram para a formação da memória do DF. O Decreto $n^{\circ} 7.492$, de 27 de abril de 1983, colocou sob a proteção do Governo do Distrito Federal (GDF) todos os documentos da NOVACAP produzidos até 1960 e considerados de valor histórico, o que foi um grande passo em direção à preservação da memória fílmica de Brasília (ARQUIVO PÚBLICO DO DISTRITO FEDERAL, 2009).

Gustavo Chauvet, então Superintendente do ArPDF, concedeu à autora uma entrevista em 2013, relatando que o Arquivo foi criado em 1985 por dois motivos: devido a um trabalho de Walter Albuquerque Mello, que se mostrou preocupado primeiramente com a documentação guardada na Secretaria de Cultura, notando posteriormente que sua preocupação abrangia toda a documentação do DF. Walter Albuquerque Mello começou, por essa razão, a brigar pela existência de um arquivo já antes do ano de 1985. O segundo motivo foi devido a visitas do Governador do DF em 1985, José Ornellas Filho, a alguns órgãos públicos, o qual observou que os documentos se encontravam espalhados e mal acondicionados em vários órgãos; assim, sentiu a necessidade de criar um arquivo que os abrigasse de maneira adequada. O Arquivo Público foi criado então, nesse contexto (informação verbal)².

A finalidade da criação do ArPDF era de preservar a documentação de caráter permanente ou histórico do GDF. Contudo, não havia preocupação com a gestão documental.

Gustavo Chauvet chamou atenção para o fato de que o ArPDF foi criado em 1985, mas já havia documentação sendo produzida no DF há vinte e cinco anos, desde 1960, quando Brasília foi fundada.

O Arquivo Público, dessa forma, é criado com vinte e cinco anos de atraso, quando um grande acúmulo de documentos relacionados ao território da capital do Brasil já havia sido produzido em diversos órgãos. A documentação da NOVACAP apresentou-se então como a mais rica no que diz respeito ao conteúdo registrado em diversos suportes relacionados à construção e história de Brasília. Segundo Gustavo Chauvet (informação verbal):

O Arquivo Público nasce recolhendo a produção da NOVACAP de 1956 a 1970 e foi um recolhimento selvagem, não houve nenhum (sic) tipo de tratamento anterior. Então havia um conjunto documental muito grande e sem nenhum (sic) tipo de tratamento arquivístico. Nesse (sic) tempo, fotos, documentação textual e talvez documentação filmográfica vieram para cá. Mas não teve nenhuma (sic) ordem nesse recolhimento.

Gustavo Chauvet relatou que o Departamento de Comunicação da NOVACAP resolveu fazer filmagens e fotografias para registrar a construção de Brasília, montando

2 Entrevista fornecida por Gustavo Chauvet no Arquivo Público do Distrito Federal em 2012. 
assim a Revista Brasília para registrar sua ação na cidade em fotografias impressas e, ao mesmo tempo, existiam os cinejornais (informação verbal).

Cinejornais com duração de 8 a 10 minutos passaram a ser realizados para registrar eventos, como a visita do Prefeito de Nova Iorque ou do Presidente de Portugal a Brasília ainda em obras. Chauvet informou na entrevista que:

Ou as autoridades entravam em um helicóptero, ou iam de jipe; alguns passavam no Núcleo Bandeirante 3 , outros iam direto para a cidade. Na maioria das vezes iam de helicóptero fazer aquela visita e o cineasta ia junto e aproveitava para filmar de cima a cidade sendo construída. Grande parte desse trabalho foi feita pelos irmãos Silva ${ }^{4}$ contratados pela NOVACAP com a finalidade de divulgar Brasília nos cinemas do Brasil. Então os cinejornais passavam nos cinemas antes dos filmes de longa-metragem.

Ao mesmo tempo em que o Departamento de Comunicação da NOVACAP registrava a construção por meio cinejornais, a Assessoria de Comunicação da Presidência da República (Agência Nacional) também cobria eventos. Por essa razão o acervo se encontra fragmentado. Uma parte está no Rio de Janeiro, no Arquivo Nacional, que cuida da documentação federal, e outra parte está em Brasília, porque as filmagens ocorreram já na nova capital. Gustavo Chauvet afirmou que seria necessária uma integração entre esses dois acervos (informação verbal).

Outro problema enfrentado, de acordo com Chauvet, concerne ao fato de não se saber se os filmes que estão no ArPDF são matrizes ou cópias. Dos filmes da NOVACAP, “o próprio Juscelino Kubitschek levou alguns para sua casa, que posteriormente foram recolhidos pelo Memorial JK”. O entrevistado descreveu que o mesmo ocorreu com o Coronel Afonso Heliodoro, que havia levado para si filmes que posteriormente foram recolhidos pelo IHGDF ou entregues ao ArPDF.

Portanto, alguns originais pertenciam ao Memorial JK e outros ao IHGDF e ao ARPDF. Todos os filmes são da NOVACAP, mas por diferentes razões acabaram sendo abrigados em três diferentes instituições e, sobre tal situação, Chauvet (informação verbal) declarou que "os filmes das outras duas instituições estão aqui. Nós temos uma sala fria para preservá-los por enquanto, além de um acordo de cooperação técnica para restaurar todos esses filmes”.

Em 2010, durante o governo de José Roberto Arruda, houve novos planos de Luiz Ribeiro de Mendonça e seu então assessor Walter Albuquerque Mello para a criação do Museu Nacional da Imagem e do Som (MNIS) em Brasília.

O objetivo do Museu seria "promover depoimentos para a posteridade, em som e imagem, das personalidades nacionais e do Distrito Federal” (ARQUIVO PÚBLICO DO DISTRITO FEDERAL, 2009, p. 25). 
Entretanto, desde a cassação do mandato de Arruda em 2010, os planos para a criação do museu ficaram estagnados. Tal fato representou um grande retrocesso no trabalho pela preservação de filmes no DF. Um museu que guardasse e difundisse as gravações de depoimentos feitas na época da construção de Brasília representaria uma instituição preocupada em preservar da melhor forma possível a memória da capital do país.

Devido à falta de instituições nesses moldes, o cineasta paraibano radicado em Brasília há pelo menos 40 anos, Vladimir Carvalho, transformou sua casa localizada no centro de Brasília em uma pequena cinemateca. Denominada Cinememória, foi fundada pelo cineasta em 1994 com o objetivo de guardar e preservar sua obra documentária em mais de 50 anos de atividade e também dos filmes feitos em Brasília e sobre Brasília (NASIASENE, [2010?]).

A pequena instituição nasceu para ser "uma provocação positiva” aos poderes públicos, para que reflitam melhor sobre a importância da criação de uma cinemateca em Brasília (SÁ, 2003, p. 126).

Vladimir Carvalho relatou que a Fundação Cinememória tem uma exposição fotográfica, câmeras, quadros, troféus, mas não são guardados filmes na Fundação: “Por um descuido qualquer podem ficar algumas cópias de filmes meus aqui esperando a decisão de levá-los para o Rio, para São Paulo ou deixar um pouco no Arquivo Público porque lá tem uma sala climatizada” (informação verbal) ${ }^{5}$.

Vladimir Carvalho, em entrevista à autora, relatou que esse "é um problema que deve ser olhado de frente” e, por isso, o cineasta criou a Fundação Cinememória. O entrevistado afirmou ter centenas de fotografias sobre o Cinema em Brasília, recortes de jornais e cartazes de filmes que, mesmo não sendo frágeis como os filmes, deveriam estar mantidos em temperatura adequada. A fotografia de Glauber Rocha fornecendo uma entrevista a Vladimir Carvalho no Festival de Cinema de Brasília de 1970 já está desbotando.

Em relação a filmes, Carvalho afirma que individualmente é quase impossível criar uma cinemateca devido aos altos custos da manutenção. O entrevistado destacou que cinematecas devem ser instituições governamentais ou privadas que possam arcar com os altos custos de se preservar filmes. "A cinemateca tem que ter paredes especiais para manter espécimes de filmes como o antigo nitrato que pega fogo com muita facilidade. O filme de nitrato tem que ficar quase num cofre” (informação verbal).

A Fundação Cinememória tem seis mil itens e uma biblioteca com quatro mil volumes. Em sua vida, Vladimir Carvalho realizou 23 filmes cujos negativos foram depositados na Cinemateca do MAM, no Arquivo Nacional e a maior parte na Cinemateca Brasileira em São Paulo para que fossem salvaguardados e eventualmente copiados para outros suportes e exibidos.

Porque aqui em Brasília eu posso no máximo guardar uma cópia de um filme temporariamente; eu estou arriscando ter o material no Arquivo Público do DF

5 Entrevista fornecida por Vladimir Carvalho em sua casa na W3, portanto na Fundação Cinememória, em 2012. 
há mais de quinze anos. Nesse momento em que estou falando com você estou perdendo minhas cópias porque filme degenera como gente, o filme morre. Se for deixado um negativo sem condições climáticas, a imagem vai desaparecer e vai virar uma pasta. E eu posso lhe (sic) afirmar que em Brasília não tem um lugar onde filmes sejam resguardados dessas ameaças. Por isso eu criei isso aqui, para sinalizar. Tantas vezes eu possa falar, na imprensa, nas palestras que faço, chamo a atenção para isso. A cinematografia de Brasília existe desde que se colocou a pedra fundamental nessa cidade. Brasília foi partejada sendo filmada, mas não tem a sua cinemateca. A cinemateca, grosso modo, é o museu do cinema. Brasília não tem. Brasília não tem um museu, na verdade, digno desse nome. Tem um lugar que se chama Museu da República onde há um esforço de abnegados que tentam manter aquilo como se fosse um lugar de exposição, mas não tem um projeto de museu. Quem dirá o cinema, que fica um pouco à margem disso tudo!

Além disso, nem todos os filmes de Vladimir Carvalho foram transferidos para suportes digitais, o que seria um empreendimento bastante dispendioso.

\section{A pesquisa}

A pesquisa adotou abordagem mista, pois o levantamento de dados foi feito por meio de questionário e entrevista.

Apresentou-se como descritiva - pois não era possível afirmar ainda se em algum local do DF os filmes estavam preservados corretamente antes da pesquisa de campo e almejou descrever as características das instituições que abrigam acervos de filmes no Distrito Federal.

Incluiu visitas a quatro produtoras fílmicas e instituições coletoras de cultura (HOMULUS, 1990) sendo: Asa Cine, Fundação Cinememória, Ligocki Z e Studio 13; e seis instituições que abrigam acervos de filmes do Distrito Federal sendo: ArPDF, Faculdade de Comunicação da UnB, Biblioteca Central da UnB, TV Câmara, TV Senado e UnB TV.

Tais instituições foram escolhidas para que fosse possível avaliar as condições em que se encontram os acervos - filmes em película, VHS, DVD e demais suportes - e coletar opiniões de cineastas e produtores de filmes sobre a preservação fílmica no DF.

O universo da pesquisa foi constituído por instituições que obedecessem a critérios específicos, assim como:

- Obterem acervos de filmes do gênero documentário ou ficção, excluindo-se reportagens jornalísticas, filmes publicitários e similares e/ou;

- Obterem acervos fílmicos sobre algum processo específico. No caso da pesquisa, tem-se por escopo a construção de Brasília e temas relacionados à construção da 
capital ou que contenham a produção de cineastas do DF e/ou;

- Serem acervos que contêm suportes fílmicos em películas 8, 16 e 35 mm, em magnético VHS e em digital DVD e/ou;

- Estarem relacionadas à produção fílmica do DF por conterem filmes produzidos no DF, por um cineasta brasiliense e/ou com tema relacionado ao DF.

Os questionários foram analisados por meio de gráficos pela ferramenta de apoio em linha Survey Monkey usada na pesquisa quantitativa. O pré-teste do questionário foi aplicado na Cinemateca Brasileira de São Paulo.

As entrevistas foram analisadas pelo método de condensação de texto com foco no significado, descrito por Kvale e Svend (2009, p. 205). Esse método de resumo é utilizado para sumarizar textos extensos.

Destaca-se que o IHGDF e o Memorial JK, importantes instituições que guardaram acervos de filmes brasilienses na década de 1960, não foram incluídos no universo da pesquisa, pois transferiram seus acervos de filmes para o ArPDF na década de 1990.

O IHGDF transferiu nove rolos de filme em 16 mm para o ArPDF em 1996. Em 1998, transferiu para a mesma instituição 19 estojos de filmes vindos da Cinemateca Brasileira. Ainda na década de 1990, o ArPDF fez uma análise do acervo recebido e constatou que três filmes se encontravam já totalmente perdidos.

Em comemoração aos 110 anos de Juscelino Kubitschek, firmou-se um acordo entre o Memorial JK e o ArPDF para que todos os filmes do Memorial fossem transferidos para o ArPDF, onde encontram-se atualmente (CIPRIANO, 2012).

\section{Resultados e reflexões}

Com relação às características de acervos fílmicos no $\mathrm{DF}$, observou-se que as instituições que os abrigam foram criadas a partir da década de 1980 e nunca cessaram de ser criadas, por isso nota-se que há uma preocupação com a salvaguarda dos acervos de filmes da região do DF.

Apesar de tais acervos terem sido criados como uma medida de emergência para que os filmes não se perdessem, não houve nenhum planejamento prévio para sua gestão e preservação.

As instituições se apresentam atualmente quase que como um depósito de documentos, abrigando no mesmo local, materiais impressos, como jornais, plantas arquitetônicas, fotografias, e filmes nos suportes de película, VHS e DVD. Sabe-se que suportes fílmicos constituídos de diferentes materiais devem ser abrigados em locais diversos, pois exigem condições de umidade e temperatura específicas.

A finalidade da criação das instituições é recolher e guardar filmes produzidos no Distrito Federal por cineastas brasilienses e/ou com tema relacionado à cidade em um único espaço. 
Tal finalidade coincide com o único critério de composição dos acervos de filmes atualmente no DF, o que chama a atenção para a necessidade de criação de novos critérios diante dos problemas de organização do acervo apresentados nos depoimentos.

Problemas como deficiências na elaboração da pesquisa para o público; falta de pessoal especializado em organizar acervos e montar sistemas de recuperação da informação; e autoria dos filmes desconhecida, também foram destacados por gestores de acervos, produtores e cineastas do DF que possuem acervos de filmes.

De acordo com os depoimentos, quando as instituições foram criadas, os filmes encontravam-se espalhados em diversos órgãos e na casa dos cineastas, fora do ambiente ideal de preservação.

Quanto aos recursos físicos e humanos nos acervos, notou-se que em $83,3 \%$ das instituições predominam filmes em suporte original e 1/3 os possui em película.

Além disso, um terço dos filmes em película se apresenta em nitrato de celulose, material que demanda instalações físicas adequadas, pois é tóxico e auto-inflamável, além de se deteriorar rapidamente quando exposto a variações climáticas.

Apesar de os filmes demandarem recursos humanos com conhecimentos especializados para lidar com o acervo, alguns dados apresentados comprovam a falta de preparo dos profissionais que trabalham nas instituições.

A maioria deles não possui especialização em Conservação e/ou Restauração, na maioria das instituições foram identificados profissionais sem formação superior e há carência de profissionais formados em Cinema. Tal situação encontra-se representada pelo Gráfico 1. 
Gráfico 1 - Formação em Conservação e/ou Restauração

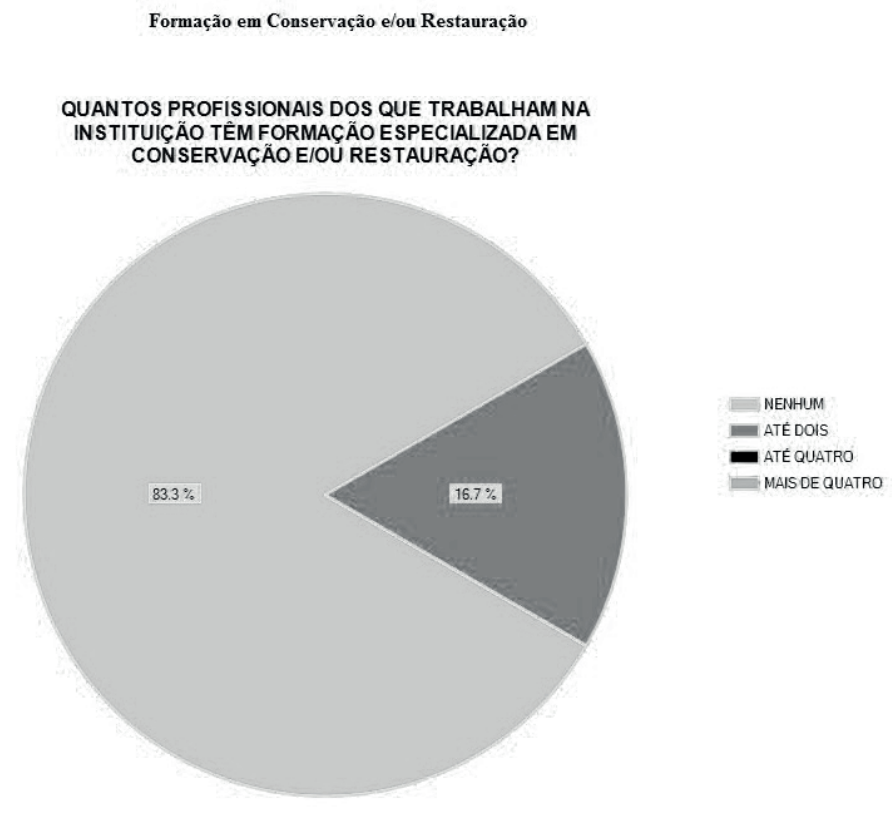

Fonte: Oliveira (2013).

O cineasta Manfredo Caldas relatou em entrevista fornecida à autora que sua formação em Cinema na cinemateca do Museu de Arte Moderna (MAM) do Rio de Janeiro ajudou-o a especializar-se melhor em restauração de filmes:

Foi um de meus primeiros trabalhos. Quando comecei a me profissionalizar, eu não só fiz os cursos específicos da cinemateca do MAM, o curso de história do cinema, de montagem e uma série de outros cursos, como passei a trabalhar na cinemateca. Então eu tinha acesso a tudo e comecei a restaurar filmes.

Notou-se a falta de projetores de película nas instituições, o que torna os filmes em película inacessíveis e dificulta sua preservação.

Considerável parte dos filmes, tanto em cores quanto em preto-e-branco, encontrase armazenada fora das condições ideais de temperatura e umidade relativa. Percebeu-se, inclusive, que em $40 \%$ das instituições os filmes em cores e em preto-e-branco parecem estar abrigados exatamente no mesmo local, sob as mesmas condições, quando cada tipo de colorização possui medidas particulares de temperatura e umidade relativa.

Os números apresentados revelaram despreparo em relação à segurança contra incêndios. Apenas metade das instituições possui extintor de incêndio. 
Revelou-se, ainda, que ocorrências nocivas ao acervo acometeram as instituições em grande porcentagem. Casos de síndrome do vinagre - pior forma de deterioração do suporte de acetato - foram registrados em $75 \%$ das instituições e a deterioração da emulsão das películas por fungos, processo considerado irreversível, já ocorreu em metade das instituições.

As maiores deficiências apontadas pelas instituições em relação a recursos físicos e humanos são instalações físicas impróprias, deficiências qualitativas de recursos humanos e limitações de espaço físico - em metade das instituições.

Nenhuma instituição considerou possuir recursos físicos, tecnológicos e humanos apropriados.

Com relação aos critérios utilizados para a incorporação de filmes aos acervos do DF, as instituições costumam apresentar um único critério, como serem filmes produzidos no Distrito Federal, por cineastas brasilienses e/ou com tema relacionado à cidade; ou, não havendo critério nenhum, guardam materiais de todos os tipos no mesmo local enquanto houver espaço para tanto. Por isso, metade das instituições declarou possuir limitações de espaço físico como ilustrado no gráfico abaixo.

Gráfico 2 - Situação dos recursos das instituições

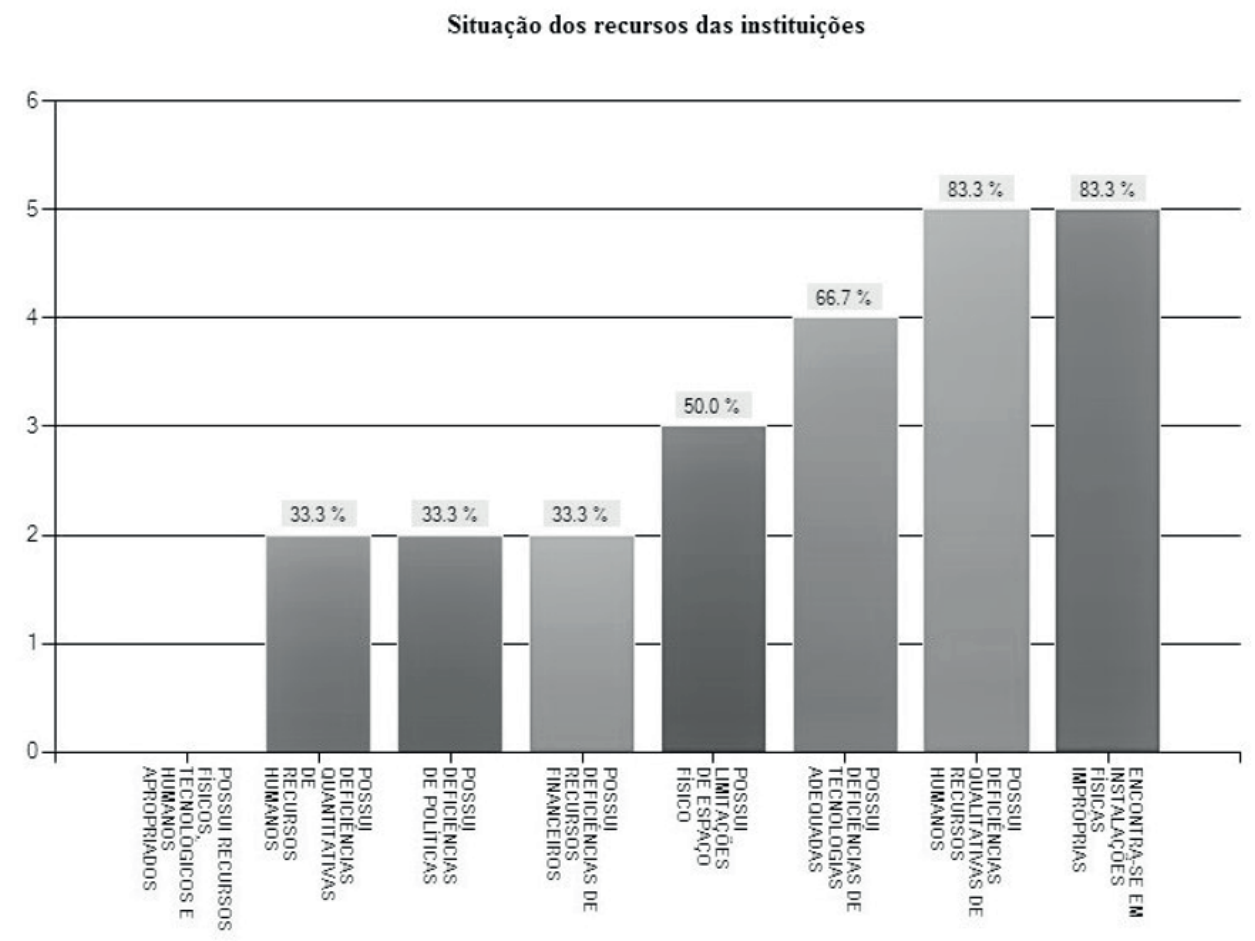

Fonte: Oliveira (2013). 
Em relação aos métodos de preservação de acervos fílmicos nas instituições do DF, ou seja, utilização de diretrizes de salvaguarda da FIAF, técnicas de restauração e indexação, migração de suportes e prática do depósito legal, pode-se dizer que são mínimos. A falta de formação dos profissionais em preservação de filmes refletiu-se de forma bastante negativa nos acervos.

Todas as instituições realizam em seus acervos de filmes apenas limpeza manual, que representa não uma técnica de restauração, mas, sim, de conservação preventiva. Além disso, um terço das instituições do DF sequer conhece os parâmetros de preservação da FIAF.

Pontos positivos são a frequência da migração de suportes e a indexação dos filmes com vistas à sua preservação e acesso, realizada em 66,7\% das instituições.

Com relação ao acesso à memória fílmica produzida/acumulada no DF, a maioria das instituições fornece acesso gratuito aos Sistemas de Recuperação da Informação.

Contudo, os cineastas e produtores afirmaram que seus filmes, de uma forma geral, não se encontram acessíveis ao público. A política de sustentação de preço das distribuidoras faz com que um número pequeno de cópias seja distribuído. Por vezes, os filmes são divulgados pelo trabalho de instituições ligadas ao cinema como a Livraria Cultura e a locadora brasiliense Cult Vídeo. A última organiza com frequência sessões de filmes pouco comercializados para o público.

Aliado a esse problema, notou-se nas entrevistas que alguns cineastas possuem apenas as matrizes dos filmes, o que representa um risco iminente à sua perda. Como citado no Programa da UNESCO (2002), caso não haja uma cópia em outro suporte, é melhor não expor o original para não o colocar em risco de ser danificado.

Quanto à percepção de gestores de acervos, de produtores e de cineastas do DF que possuem acervos de filme a respeito de questões relevantes sobre tais acervos, a maioria dos entrevistados relatou já ter perdido filmes por estarem em locais inadequados. Apenas um relatou não ter perdido material por ter começado suas filmagens já na era digital, mas ainda assim sente-se inseguro com relação ao tempo de sobrevida das mídias digitais.

Os relatos atribuíram a Brasília uma produção fílmica expressiva em quantidade e qualidade, sobretudo por influência dos primeiros cineastas que vieram para a cidade para criar o Curso de Cinema na UnB. Há consenso por parte dos entrevistados de que a produção fílmica na cidade continua a ser bastante expressiva, o que pode ser notado pelo fato de o Festival de Brasília do Cinema Brasileiro ser um dos maiores do país.

Contudo, a preservação de filmes exige investimento financeiro e especialização dos recursos humanos. Porém, o que se tem notado é a falta de investimento do governo nesse quesito, ou pela falta de visão sobre os bons resultados que a preservação fílmica traria para a memória da cidade, ou pela falta de interesse em se manter essa memória.

Aqueles que desejam saber mais sobre a história de Brasília, ou realizar filmes na cidade ficam sem referências do passado para construir suas obras ou reconstituir em sua imaginação fatos marcantes sobre a capital desde sua inauguração. 
Vários entrevistados relataram que a existência de uma cinemateca em Brasília, que reunisse todos os filmes em um só local tornando-os acessíveis, facilitaria o acesso à memória da cidade.

Atualmente, alguns filmes produzidos na capital se encontram em outros Estados do Brasil e sem cópia no DF, o que os torna ainda mais inacessíveis para os brasilienses. Tal fato ocorre porque os cineastas ficam impossibilitados de preservar os próprios filmes devido aos altos custos demandados para tal prática e, dentre as instituições do Brasil aptas a receber filmes e mantê-los preservados, foram citadas a Cinemateca Brasileira de São Paulo, a Cinemateca do MAM e o Arquivo Nacional do Rio de Janeiro.

O que tem favorecido a preservação dos filmes brasilienses é sua boa divulgação, que gera cópias para canais de televisão por exemplo. Quanto mais cópias, mais difícil torna-se a possibilidade de o filme desaparecer.

Notou-se que grande parte dos filmes do DF, tanto de acervos particulares como de órgãos públicos, vem sendo depositada no ArPDF há um tempo, representando essa instituição o único local para guarda de filmes na capital, atualmente.

\section{Conclusão}

Após a Segunda Guerra Mundial, ao mesmo tempo em que se vivia a chamada explosão informacional, espalhou-se pelo mundo a ideia de criar acervos fílmicos. Notou-se que a informação registrada possuía, então, inúmeros suportes, dentre eles o filme.

Visto que o filme registra a informação, não só do ponto de vista da evolução do Cinema, mas igualmente, dos conteúdos desenvolvidos nos filmes, que são valorosas informações a serem preservadas, a pesquisa a que se refere o presente artigo representa uma contribuição para a Ciência da Informação por criar um alerta para o atual panorama de preservação em que se encontram os filmes brasilienses.

Em relação a fatos históricos sobre a construção de um movimento cinematográfico no DF e questões envolvendo a preservação de filmes na capital, as descrições foram muito similares entre os entrevistados.

Concluiu-se, a partir dos dados recolhidos, que a produção de filmes brasilienses é expressiva em quantidade e qualidade, além de ser constante desde a criação da cidade, mas nunca houve um lugar no Distrito Federal onde os acervos de filmes produzidos pudessem ser guardados em segurança.

Além disso, as práticas que levam à preservação dos filmes são caras e exigem dedicação de tempo e especialização, o que as torna difíceis de serem executadas pelos próprios cineastas e produtores.

Atualmente, no DF, as instituições que possuem acervos de filmes não agregam as características necessárias para preservar tais acervos. Notaram-se fortes deficiências nos recursos humanos e nas instalações físicas que guardam os acervos. 
Não há uma cinemateca no Distrito Federal para guardar os filmes que estão sendo produzidos e aqueles que correm o risco de se perder, e essa responsabilidade vem sendo transferida para o ArPDF, que não tem suporte físico nem recursos humanos para manter os filmes como é feito em uma cinemateca devidamente equipada.

No geral, para manter os filmes em segurança, grande parte dos cineastas os envia para São Paulo ou para o Rio de Janeiro. O ArPDF muitas vezes é utilizado como um local de guarda temporária ou de emergência.

Apesar dos dados revelarem que não há uma instituição que guarde os filmes adequadamente no DF, o ArPDF parece estar fazendo um grande esforço em estruturar a instituição para se aproximar dos moldes de uma cinemateca.

A criação de uma cinemateca no DF apresenta-se, assim, como uma medida urgente para a salvaguarda da memória de Brasília e divulgação dos filmes brasilienses. Além disso, tal instituição ajudaria na formação prática e teórica de cineastas e fomentaria discussões sobre a cultura cinematográfica brasileira e, consequentemente, da brasiliense, criando assim uma instituição ligada à educação e à cultura com raízes na produção artística da própria cidade.

Retomando-se o objetivo geral do presente trabalho, de descrever como e onde é realizada a preservação de acervos fílmicos do Distrito Federal, pode-se concluir que a tentativa de preservação é realizada em poucas instituições que praticamente armazenam os filmes sem os preservar.

A prática de transferência de suportes aumentaria o acesso aos filmes e representaria uma das formas de preservação do material fílmico; contudo, não há atualmente no DF uma instituição que realize tal ação e disponibilize os filmes.

As instituições públicas que abrigam filmes firmam tal prática sobre uma base insegura, sem equipamentos, instalações físicas ou pessoal adequados.

Os filmes brasilienses que se encontram guardados com mais segurança não estão no Distrito Federal, o que os torna inacessíveis para os brasilienses. Os que ficam na cidade de Brasília correm o risco de se perder rapidamente.

A situação presente do acervo fílmico produzido ao longo da história de Brasília está sendo impactada em duas frentes: a de acesso e a de preservação.

\section{Referências}

ALVIM, C.A.; BUENO, V. A.; GUIMARÃES, M. A. Os cine-jornais sobre o período da construção de Brasília. Brasília: FUNARTE, 1983.

ARQUIVO PÚBLICO DO DISTRITO FEDERAL. Guia: Arquivo Público do Distrito Federal. 7.ed. Brasília: ArPDF, 2009.

CARVALHO, V. Cinema candango: matéria de jornal. Brasília: Cinememória, 2002.

CIPRIANO, L. Memorial celebra 110 anos de JK. GDF [Site]. Disponível em: http://www.df.gov.br/noticias/ item/3509-memorial-celebra-110-anos-de-jk.html. Acesso em: 12 dez. 2012. 
PRESERVAÇÃO DE ACERVOS FÍLMICOS NO DISTRITO FEDERAL

CORREA JÚNIOR, F. D. A cinemateca brasileira: das luzes aos anos de chumbo. São Paulo: UNESP, 2010.

DINO Cazzola: uma filmografia de Brasília. Produção executiva Vera Affonso. Direção de Andréa Prates e Cleisson Vidal. São Paulo: Terra Firme, [2012]. Disponível em: http://terrafirmeprodutora.com.br/site/dinocazzola/. Acesso em: 20 jul. 2012.

HALBWACHS, M. A memória coletiva. São Paulo: Centauro, 2006.

HOMULUS, P. “Museums to libraries: a family as collecting institutions”. Art Library Journal, v. 15, n. 1, p. 11-13, 1990.

KVALE, S.; SVEND, B. InterViews: learning the craft of qualitative research interviewing. Los Angeles: Sage, 2009.

MENDES, M. S. Paulo Emílio, a UnB e o Cinema: permanências e continuidades. In: Festival 40 anos: a hora e vez do Cinema brasileiro. Brasília: Secretaria de Cultura, 2007.

MORICONI, Sé. Cinema: apontamentos para uma história. Brasília: Instituto Terceiro Setor, 2012.

NASIASENE,A. “Umacinematecabrasiliense:aFundaçãoCinememóriacomomuseucontemporâneodaimagem e do som especializado em cinema”. [Portal] Fundação Cinememória, Brasília, [2010]. Disponível em: http:// www.fundacaocinememoria.com.br/index.php?option=com_content\&view=article\&id=46\&Itemid=58. Acesso em: 15 ago 2012.

SÁ, G. Acervo do polo de cinema é transferido para o arquivo público do DF. Correio Braziliense, Brasília, 31 jul. 2012. Disponível em: http://www.correiobraziliense.com.br/app/noticia/diversao-e-arte/2012/07/31/ interna_diversao_arte,314373/acervo-do-polo-de-cinema-e-transferido-para-o-arquivo-publico-do-df. shtml. Acesso em: 19 ago 2012.

SÁ, R. M. Cineastas de Brasília. Brasília: R. M. Sá, 2003.

TESOUROS da construção de Brasília permanecem guardados. Correio Braziliense [on line]. Brasília, 7 fev. 2011. Disponível em: http://www.correiobraziliense.com.br/app/noticia/cidades/2011/02/07/interna_ cidadesdf,236356/tesouros-da-construcao-de-brasilia-permanecem-guardados.shtml. Acesso em: 10 jan. 2013.

UNESCO. Divisão da Sociedade da Informação. Memória do mundo: diretrizes para a salvaguarda do patrimônio documental. [S. 1.], fev. 2002. Preparado para a UNESCO por Ray Edmondson. Disponível em: http://www.UNESCO.org.uy/ci/fileadmin/comunicacion-informacion/mdm.pdf. Acesso em: 22 jul. 2010.

ZANIN, L. Dino Cazzola: uma filmografia de Brasília. Blog do Estadão, São Paulo, 26 mar. 2012. Disponível em: http://blogs.estadao.com.br/luiz-zanin/dino-cazzola-uma-filmografia-de-brasiia/. Acesso em: 14 mar. 2012.

\section{Angélica Gasparotto de Oliveira}

Doutoranda no Departamento de Artes da Universidade de Bolonha, onde desenvolve uma tese sobre a adaptação de laboratórios tradicionais de restauração de filmes às técnicas digitais. Mestre em Ciência da Informação pelo Programa de Pós-Graduação em Ciência da Informação (PPGCInf) da Universidade de Brasília (UnB), com uma dissertação intitulada "Preservação de Acervos Fílmicos no Distrito Federal”. Formada em Biblioteconomia, também na UnB, com monografia intitulada "Microtesauro em Cinema”. É membro da Associação Brasileira de Preservação Audiovisual (ABPA) e especializada em produção e roteiro de filmes pela New York Film Academy (NYFA). Possui ainda especialização em restauração de filmes pela Federação Internacional de Arquivos 
de Filmes (FIAF). Trabalhou com a catalogação de documentos sonoros e livros na Universidade de Brasília e na Organização dos Estados Ibero-americanos e ganhou experiência em restauração e preservação de filmes no laboratório ANIM da Cinemateca Portuguesa. E-mail: angelica. gasparotto@gmail.com.

Recebido em: 20.07.2016

Aprovado em: 16.11.2019 